\title{
Rate of a maintained operant as a function of temporal position within a session
}

\author{
WILLIAM L. PALYA and DONALD E. WALTER \\ Jacksonville State University, Jacksonville, Alabama
}

\begin{abstract}
McSweeney and her colleagues (e.g., McSweeney, Hatfield, \& Allen, 1990) have demonstrated reliable, large magnitude rate changes in maintained operants within daily sessions under a wide variety of reinforcement schedules. The present paper examined the role of schedule of reinforcement, reinforcement rate, and total amount of food access in determining those within-session rate changes. When median rates across birds were considered, all procedures resulted in a brief period of an increasing rate, followed by a modest rate loss across the major portion of the session. However, not all individuals exhibited that pattern. When the amount of food access per session was limited by lower reinforcement rates, shorter sessions, or shorter reinforcement durations, the magnitude of the withinsession rate change was reduced from that occurring without those constraints. Additionally, under the conditions that produced strong within-session rate changes, the magnitude of the within-session rate loss was correlated with the bird's body weight. These effects are consistent with what is typically labeled satiation.
\end{abstract}

McSweeney and her colleagues (McSweeney, Hatfield, \& Allen, 1990; McSweeney \& Hinson, 1992; McSweeney, Roll, \& Weatherly, 1994) have documented systematic changes in operant responding as a function of temporal position within each daily exposure to a schedule of reinforcement (i.e., a session). Their extensive functional analyses have typically indicated a relatively short duration period during which the response rate increases, followed by a generally decreasing rate throughout the remainder of the session. This bitonic rate change is of importance for three reasons. First, to the degree that it is reliable, it must be studied if a coherent and complete understanding of schedule control, and a general understanding of behavior, is to be accomplished. Second, a changing rate across the session would mean that any single index of behavior collapsed across a session can correctly represent only that, or larger quantal units, rather than behavior in general. Finally, if behavior systematically changes across a session, then any withinsession experimental treatment confounds that treatment with the bitonic effect. There would be important ramifications of this confound with respect to our body of accumulated knowledge (McSweeney, 1992).

However, the literature suggests that the bitonic withinsession effect may not be ubiquitous. Examination of cu-

Portions of this paper were presented at the annual meeting of the Psychonomic Society, 1995. The authors gratefully acknowledge the contributions of Helen Bush and Josey Chu for running the animals; Robert Allan, Edmond Venator, Robert Kessel, and Guido Gebauer for critical discussions; Peter Killeen and Frances McSweeney for comments on an earlier draft of this paper; and Elizabeth Palya for contributions in all phases of this research. Correspondence and requests for reprints should be sent to W. L. Palya, Department of Psychology, Jacksonville State University, Jacksonville, AL 36265 (e-mail: palya@, sebac.jsu.edu). mulative records in Ferster and Skinner (1957) do not suggest a rate change on the order of $450 \%$ across a session, as was obtained by McSweeney et al. (1990). The current practice of collapsing data across a session into a single index indicates that the bitonic effect either had not been noticed, or had not been considered significant by most researchers before McSweeney's 1992 observation. Moreover, studies explicitly depicting behavior as a function of time in the session have not always shown the bitonic effect (McSweeney et al., 1990; Palya, 1992).

There is also variability in the magnitude of the withinsession rate change. It is very strong in some circumstances, most notably in rats on pseudomultiple schedules with high reinforcement rates and session lengths which result in a substantial number of reinforcers. But the effect appears minimal in other situations, most notably with pigeons with low reinforcement rates and session lengths which result in fewer reinforcers than are necessary to maintain the bird at its $80 \%$ body weight (McSweeney, Roll, \& Cannon, 1994).

Finally, in some cases, the within-session rate change appears to be a prototypical, clear, steady curvilinear rate increase across the first $20 \mathrm{~min}$ of a session, followed by a subsequent steady curvilinear rate decrease to the end of the session, whereas in other situations, the increase or the decrease or both are absent. In fact, an initial shortduration rate decrease at the session onset, as well as a slow steady rate increase across the entire session, has been shown (Palya, 1992).

Although none of these inconsistencies in any way refutes the bitonic effect, they do justify caution before arguing that the effect is universal and always of consequence. The fact that the bitonic, within-session rate change is very strong and reliable in some circumstances, but ab- 
sent, negligible, inverted, or confined to only one portion of a session in other situations, requires clarification.

To date, McSweeney's research suggests that the effect has motivational characteristics rather than associative ones. The bitonic effect: (1) can occur on the first session of exposure (McSweeney, 1992), (2) changes as a function of the reinforcement rate (McSweeney, Roll, \& Cannon, 1994), (3) is a function of absolute reinforcement number (or time) from the session onset (McSweeney, Weatherly, \& Swindell, 1995), (4) continues across sessions when there is only a short separation between the sessions (McSweeney \& Johnson, 1994), and finally (5) does not affect response accuracy (McSweeney, Weatherly, \& Swindell, 1996).

It follows that the bitonic effect could be a function of food "handling" capacity (Richter, 1927). The core idea of food handling capacity is that some quantity of food could be too much for a single "meal," while still being too little for a day's ration. Collier, Hirsch, and Kanarek (1977) have reviewed this effect and have shown that animals rarely eat to daily homeostatic repletion in a single bout. Rather, they eat many small meals spread throughout the day. McSweeney and her associates have lent some credence to this potential explanation for the bitonic effect by showing that factors which did not change the absolute volume of the reinforcer did not alter the bitonic effect, whereas changing the volume of the reinforcer did alter the distribution of responding across the session (Roll, McSweeney, Johnson, \& Weatherly, 1995).

In an effort to clarify the factors controlling the bitonic effect, the present paper documents the results of procedures specifically implemented to measure behavior change as a function of position within a session. Additionally, the paper provides a reanalysis of procedures which would contribute to the understanding of the bitonic effect, but which had been originally intended to answer other questions (Experiment 1 ).

\section{EXPERIMENT 1}

The results from this set of procedures were used to examine the degree to which reinforcement rate and schedule of reinforcement governed the occurrence of a bitonic response rate change across a session. Each of 12 birds was exposed to five reinforcement rates under each of three different schedules of reinforcement ( 15 phases). The three schedules were matched at each reinforcement rate. Because reinforcement rate, session duration, and number of food presentations cannot be independently varied, the session length was adjusted in order to limit food access to no more reinforcers than were necessary to maintain the birds at their $80 \%$ weight.

\section{Method}

Subjects. Twelve adult, experimentally naive pigeons, obtained from a local supplier, were used. They were housed under a 19:5-h light:dark cycle in individual cages, with free access to water. All were maintained with pelletized laying mash. As determined by each bird's presession body weight, the number of reinforcers in a ses- sion was adjusted from its typical value of 50 , so that each bird would be at $80 \%$ of its free-feeding weight at the beginning of the next session. The birds very rarely varied by more than a percent or two from their prescribed $80 \%$ weights when weighed before a session.

Apparatus. Five experimental chambers were used. The interior of each was a $30-\mathrm{cm}$ cube painted white. A stimulus panel served as one wall of the chamber. It had a feeder aperture medially located $8 \mathrm{~cm}$ above the grid floor. Three symmetrically positioned response keys, $2 \mathrm{~cm}$ in diameter, were located $9 \mathrm{~cm}$ apart, $19 \mathrm{~cm}$ above the grid floor. To operate them required a force of approximately .15 N. The translucent Plexiglas keys could be transilluminated lime green by a stimulus projector containing a Rosco theatrical color filter. Two houselights were located on the stimulus panel $28 \mathrm{~cm}$ above the grid floor and $9 \mathrm{~cm}$ apart. Ventilation was provided by an exhaust fan mounted on the outside of the chamber. A white-noise source provided ambient masking noise. The houselights and keylights were off and the magazine light was on during food presentation.

Stimulus events were controlled and keypecks were recorded by a computer system (Palya \& Walter, 1993). The computer archived the time of each stimulus and response event in 1 -msec "ticks." Subsequent data extraction and analysis routines provided the resulting behavioral indices. Complete raw data event logs of all research are maintained for 10 years and are available via internet upon request (see the authors' note).

Procedure. Each bird was exposed to a series of variable ratio (VR) schedules of differing requirements. These schedules provided a 3-sec reinforcer for the first keypeck following a variable number of keypecks with the specified mean. A 20 -element FleshlerHoffman series (Fleshler \& Hoffman, 1962) was used to generate the distribution of response requirements for each VR schedule. In separate phases, each bird also received variable-interval (VI) schedules and VI+ schedules (McDowell \& Kessel, 1979) yoked to the reinforcement rate obtained under each VR procedure. A VI+ schedule is a synthetic schedule that reinforces the first response after a temporal interval which itself is a function of the average interresponse time (IRT) for that interreinforcement interval (IRI). For example, a VI+ 100-sec schedule provides a reinforcer for the first response after, on average, 100 times the average IRT in that IRI. In this way, faster responding results in a higher reinforcement rate, but the probability that a specific IRT will be followed by reinforcement is the same as that in an interval schedule, rather than in a ratio schedule. Because of the way it was scheduled, a bird's $\mathrm{VI}+$ schedule necessarily had the same mean reinforcement rate as did the VR to which it was yoked. Each bird also received a VI schedule yoked to its reinforcement rate under the VR. Note that for ease of designating the appropriate schedule value for comparison, and for ease of labeling the VI and VI+ values for the 12 birds under the 15 conditions, those schedule values were specified as the VR value to which they were yoked. For example, a VI which was yoked to a VR 100 (i.e., a VI prime schedule or VI'100) had the same IRI as that bird's VR 100. Across birds, the mean IRI for the $\mathrm{VI}^{\prime} 10,50,100,200$, and 400 schedules were 5, 24, 50,103, and $218 \mathrm{sec}$, respectively. This simple labeling convention eliminated the need to specify 60 different VI schedule values and the tables indicating which VI value corresponded to which VR values for each bird.

Each procedure was implemented with each bird counterbalanced (balanced across birds) until responding was judged stable by timeseries analysis on eight consecutive mean daily response rates (Tryon, 1982; von Neumann, Kent, Bellinson, \& Hart, 1941; Young, 1941) and the judgment of stability was confirmed by visual inspection. The session duration for a bird on a given day was determined by the number of reinforcers necessary to maintain the bird at its $80 \%$ body weight or 50 reinforcers ( 30 when the schedule value was 400 ), whichever was smaller. The session duration, therefore, varied somewhat from day to day and more substantially from schedule to schedule. For example, at the lowest reinforcement rate, sessions were approximately $100 \mathrm{~min}$ long, whereas at the highest 
reinforcement rate, sessions were approximately 4 min long. The session length and, therefore, the opportunity to observe longduration within-session effects necessarily varied because schedule value, amount of food presented, and session length could not be simultaneously controlled. Simply put, each bird was exposed to each of the following procedures for between 10 and 30 sessions: VR 10 , $50,100,200$, and $400 ; \mathrm{VI}+10,50,100,200$, and $400 \mathrm{sec}$; and $\mathrm{VI}^{\prime}$ $10,50,100,200$, and $400 \mathrm{sec}$. The VR 400 did not maintain reliable responding in Bird 440 . Therefore, the data for that bird were not included in the analysis of variance (ANOVA).

\section{Results and Discussion}

Description of behavior. Overall, the procedures of Experiment 1 resulted in only a modest decline in rate across the session. None of the reinforcement rates or schedules of reinforcement resulted in large withinsession rate changes when total amount of food access was held constant by adjusting the session length. Single, straight-line, least squares characterizations showed that the three schedules and the five reinforcement rates all had similar slopes. An ANOVA ( 11 subjects $\times 3$ schedules $\times 5$ reinforcement rates) indicated that the obtained slope differences due to schedules and reinforcement rates were not significant ( $p<.99$ and .94 , respectively). The median slope varied from -0.07 to -0.19 for schedules (collapsed across reinforcement rates and birds) and from -0.01 to -0.48 for reinforcement rates (collapsed across schedules and birds). Collapsed across schedules, reinforcement rates and birds, the median slope was -0.06 . Lastly, while many functions (as characterized by 20 -sec bins) showed atypical responding immediately following the beginning of the session, many other functions appeared, for the most part, to be relatively linear throughout the session.

If time in the session controls two distinct processes, then the parameters of a two-straight-line fit could be used as a relatively powerful but conceptually simple analytical technique to identify the general characteristics of those two processes. To that end, the mean number of responses averaged across the last five sessions, in each consecutive 20 -sec bin throughout the session, under each procedure, was subjected to a Fourier-based smoothing algorithm to reduce the $y$-axis noise (Press, Flannery, Teukolsky, \& Vetterling, 1989). Fourier smoothing removes linear trend from a data set, does a low-pass filter, and then reinstalls the linear trend. The session was then iteratively dichotomized into two data sets at each 20 -sec bin boundary and best-fit straight lines were determined for the data in each of the resulting segments of the data set. The fits were not forced to intersect at the breakpoint. The bin boundary of the split and the two straight lines which resulted in the least total residual error across the two portions of the session were taken as the breakpoint and the two best-fit straight lines for that data set. Actual residual error was then redetermined with the original unsmoothed data.

The first- and second-segment slopes were subjected to an ANOVA ( 11 subjects $\times 3$ schedules $\times 5$ reinforcement rates). The first-segment slopes did not differ as a function of schedule or reinforcement rate $(p<.66$ and
.18 , respectively). The second-segment slopes did differ as a function of schedule $(p<.04)$, but not as a function of reinforcement rate $(p<.84)$. The interaction was also significant $(p<.01)$. In order to better understand the source of that interaction and the marginal significance of the schedule effect, an additional ANOVA of the second-segment slopes which excluded the highest reinforcement rate was carried out. It was not significant $(p<.18$ and .92 for either schedules or reinforcement rates, respectively).

There was considered to be insufficient justification to accept that the treatments differentially affected the slope of the best-fit straight line for either the first or the second segment. Therefore, the 12 initial slopes (one for each bird) under each of the 15 procedures were displayed in a single frame. Similarly, the second-segment slopes were displayed in a single frame. These frames were taken to depict the within-session effect across a broad range of reinforcement rates for three schedules of reinforcement. The upper left frame of Figure 1 provides the lines fit to the initial segments of the within-session rate change normalized to the last data point preceding the breakpoint (a "backward" plot). The center left frame provides a similar but "forward" depiction for the secondsegment fits. In this case, the functions were normalized to the first data point following the breakpoint. To the right of each of these frames is a histogram of the respective slopes for all 12 birds across all 15 procedures.

As can be seen, the initial line segments shown in the top left frame vary in both duration and slope. Most slopes were positive. The median slope was +3.6 and is designated with a dotted line which extends from the $x$ axis through the normalization point. As can be seen, there were a substantial number of negative as well as near zero slopes. The first and third quartiles of the slopes were at -0.47 and +19.97 , respectively. With the bin boundaries used in the distribution of slopes depicted in the upper right frame, the modal slope was between -5 and 0 . The next most frequent slope was from 0 to +5 .

The data for the latter part of each session shows that the best-fit line segments exhibited much less variability in slope. Although there were a few outliers, most often there was a consistent modest decline in rate across the second portion of the session. The median slope was -0.09 and is designated with a dotted line which extends from the normalization point past the $x$ extent of the frame. The first and third quartiles of the slopes were at -0.25 and +0.07 , respectively. With the bin boundaries used in the distribution of second-segment slopes depicted in the right center frame, the modal slope was between -2 and 0 . The next most frequent category was between 0 and +2 .

The bottom two frames of Figure 1 provide the slope differences (second slope minus first slope) and the distribution of breakpoints, respectively. The difference in the slopes of the best linear fits of the first and second portion of the session is an alternative way to characterize the magnitude of the bitonic effect. Not surprisingly, the differences in the two slopes for each individual bird show that for the most part, the two slopes were very sim- 

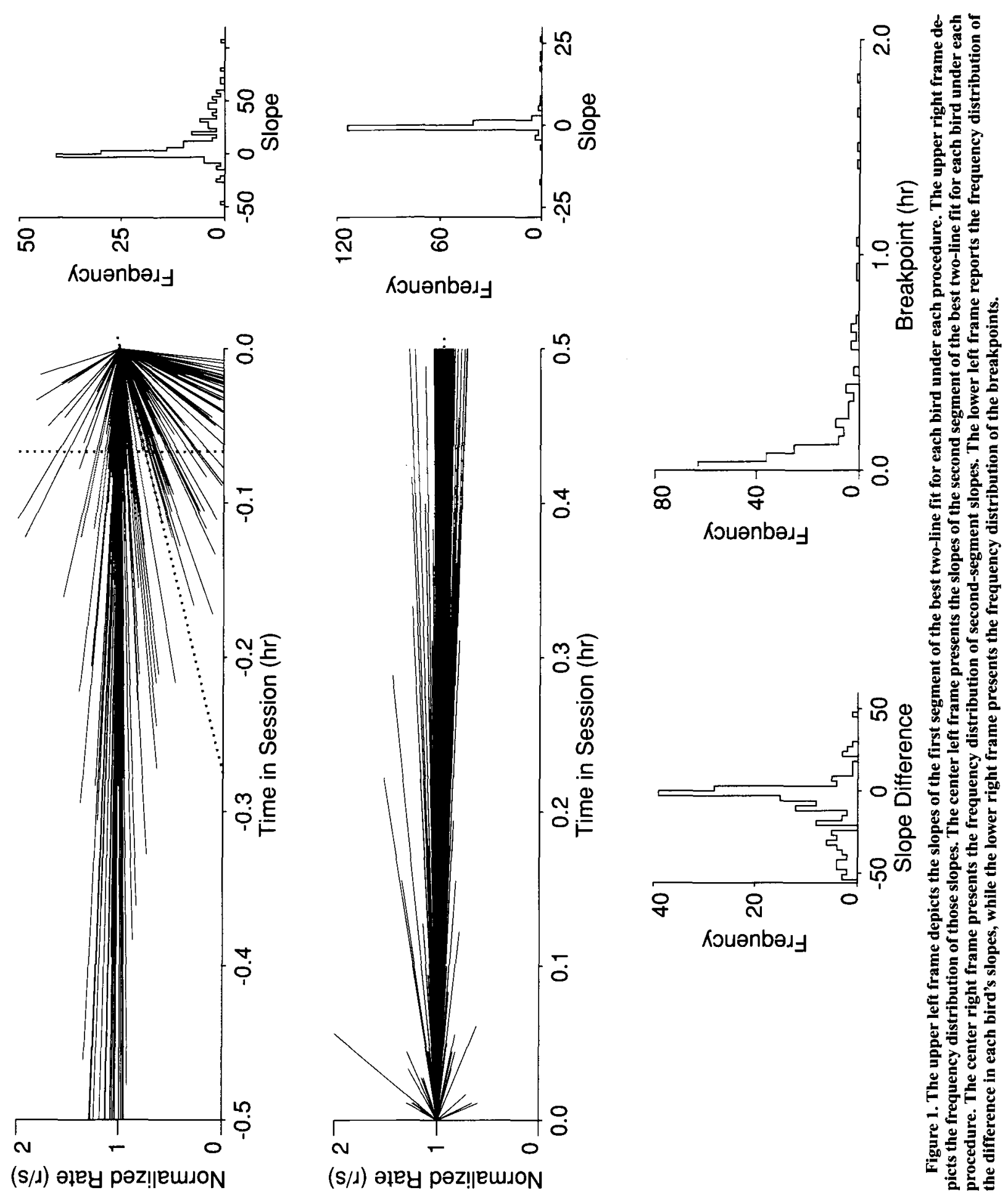

(s/ג) әlеy pəz!|ешлоN

(s/ג) әॄеy pəz!|eusoN 
Table 1

Median Breakpoints in Minutes for Two-Line Fits of Within-Session Rate Changes in Experiment 1

\begin{tabular}{rrrr}
\hline & VR & VIt & VI' $^{\prime}$ \\
\hline 10 & 1.67 & 1.67 & 3.17 \\
50 & 1.17 & 3.50 & 4.17 \\
100 & 5.17 & 2.50 & 2.83 \\
200 & 6.67 & 10.00 & 7.67 \\
400 & 5.33 & 8.50 & 7.50 \\
\hline
\end{tabular}

ilar. This indicated that there was little change in the rate of change between the first and second segment of a session. The change that did occur was most typically a greater deceleration (or less acceleration). The median slope difference was -4.25 . The interquartile range of the slope differences was from +0.15 to -24.37 .

An ANOVA of the breakpoint data (11 subjects $\times 3$ schedules $\times 5$ reinforcement rates) indicated that the schedule effect was not significant $(p<.54)$, but that the reinforcement rate effect was significant $(p<.01)$. The reinforcement rate effect was also significant if the highest reinforcement rate treatment was excluded $(p<.01)$, indicating that the effect was robust. An analysis of the breakpoint distribution shows that half the breakpoints occurred within the first $.07 \mathrm{~h}(4 \mathrm{~min})$ of a session. The first and third quartiles were at 1.67 and $10.00 \mathrm{~min}$, respectively. The vertical dotted line in the upper left frame of Figure 1 depicts the session start if the normalization point were at the median breakpoint (i.e., the normalization point minus the median breakpoint).

Table 1 provides the median breakpoints for the 12 birds under each of the 15 conditions of Experiment 1 . It shows that there was a general trend toward breakpoints later in the session with decreases in the reinforcement rate (longer session lengths). There was an exception; the very lowest reinforcement rate showed a slightly earlier breakpoint than did the next leaner schedule. An important aspect of the findings illustrated in the table is that the shifts in the median breakpoints were not nearly of the same magnitude as the increase in session length. This, therefore, suggests some upper limit in the shift in the breakpoint toward latter portions of the session with increases in session length.

Summary. In general terms, Experiment 1 showed that variations in reinforcement rate and schedule of reinforcement did not produce a large magnitude within-session rate change if the amount of food provided during each session was controlled by adjusting the session length. On the other hand, there were also similarities with the results obtained by McSweeney. There was a short initial period of accelerating rate followed by a relatively long period of a decelerating rate. In addition, the present findings showed that the initial rate increase at the beginning of the session appeared to last longer when the reinforcement rate was lower (and the session length, longer). The present findings differed from those of McSweeney in that the bitonic effect was very much smaller in magnitude in the present case and the breakpoint oc- curred earlier in the session. Additionally, the present findings exhibited substantially more variability than that found by McSweeney.

The daily running procedure implemented in the present experiment was the standard used in this laboratory. Birds are run 7 days a week with virtually no exceptions. A bird's session length is determined by the number of reinforcers necessary to maintain that bird at its $80 \%$ weight or 50 reinforcers (unless session times get long), whichever is smaller. Sessions end at the termination of the last reinforcer scheduled for that session. If a bird is post fed, it occurs $2-4 \mathrm{~h}$ after the session. With very rare exceptions, birds are within $1 \%-2 \%$ of their $80 \%$ weight at the beginning of the next session, 23-25 $\mathrm{h}$ later. The lack of a dramatic bitonic rate change across the session may have been due to this running procedure (but see Roll et al., 1995). In Experiment 2, we explored the effect of an alternate running procedure. The variation explored in Experiment 2 allowed the number of food presentations to exceed the minimum necessary to maintain a bird at its $80 \%$ weight.

\section{EXPERIMENT 2}

This experiment was used to better determine the population frequencies of the bitonic effect in schedule-controlled behavior when session lengths were held constant regardless of the number of reinforcers delivered. Birds were exposed to phases which provided successively higher reinforcement rates, while the session length was held constant at $1 \mathrm{~h}$. The number of reinforcers delivered within each session was allowed to increase without limit as the reinforcement rate increased. Additionally, the body weight criterion for exposing a bird to its procedure on a given day was relaxed and made more comparable to that specified by McSweeney.

\section{Method}

Subjects. Forty-five adult pigeons of various breeds and sizes (free-feeding weights ranged from 309 to $853 \mathrm{~g}$ ) obtained from a local supplier were used. They were housed under a 19:5-h light:dark cycle in individual cages, with free access to water. All were maintained with pelletized laying mash.

Apparatus. Eleven experimental chambers were used. The interior of each was a $30 \times 30 \times 34 \mathrm{~cm}$ high cube. An unfinished aluminum panel served as one wall of the chamber; the other sides were painted flat white. The stimulus panel had a feeder aperture $5 \mathrm{~cm}$ in diameter, medially located $10 \mathrm{~cm}$ above the grid floor. Three symmetrically positioned response keys, $2 \mathrm{~cm}$ in diameter, were located $9 \mathrm{~cm}$ apart, $29 \mathrm{~cm}$ above the grid floor. To operate them required a force of approximately $0.15 \mathrm{~N}$. The 11 chambers contained infrared sensors in the feeder vestibule. A transmitter/detector pair was positioned immediately above and horizontally across the food access hole in the bottom of the vestibule; its output was considered a "bite." Comparison of its output with the descriptions of human observers indicated that this sensor measured pecking at the food (if not necessarily actual eating). The translucent Plexiglas keys could be transilluminated lime green by a stimulus projector containing a Rosco theatrical color filter. Two houselights directed upward were located on the stimulus panel $32 \mathrm{~cm}$ above the grid floor. Ventilation was provided by an exhaust fan mounted on the outside of the 

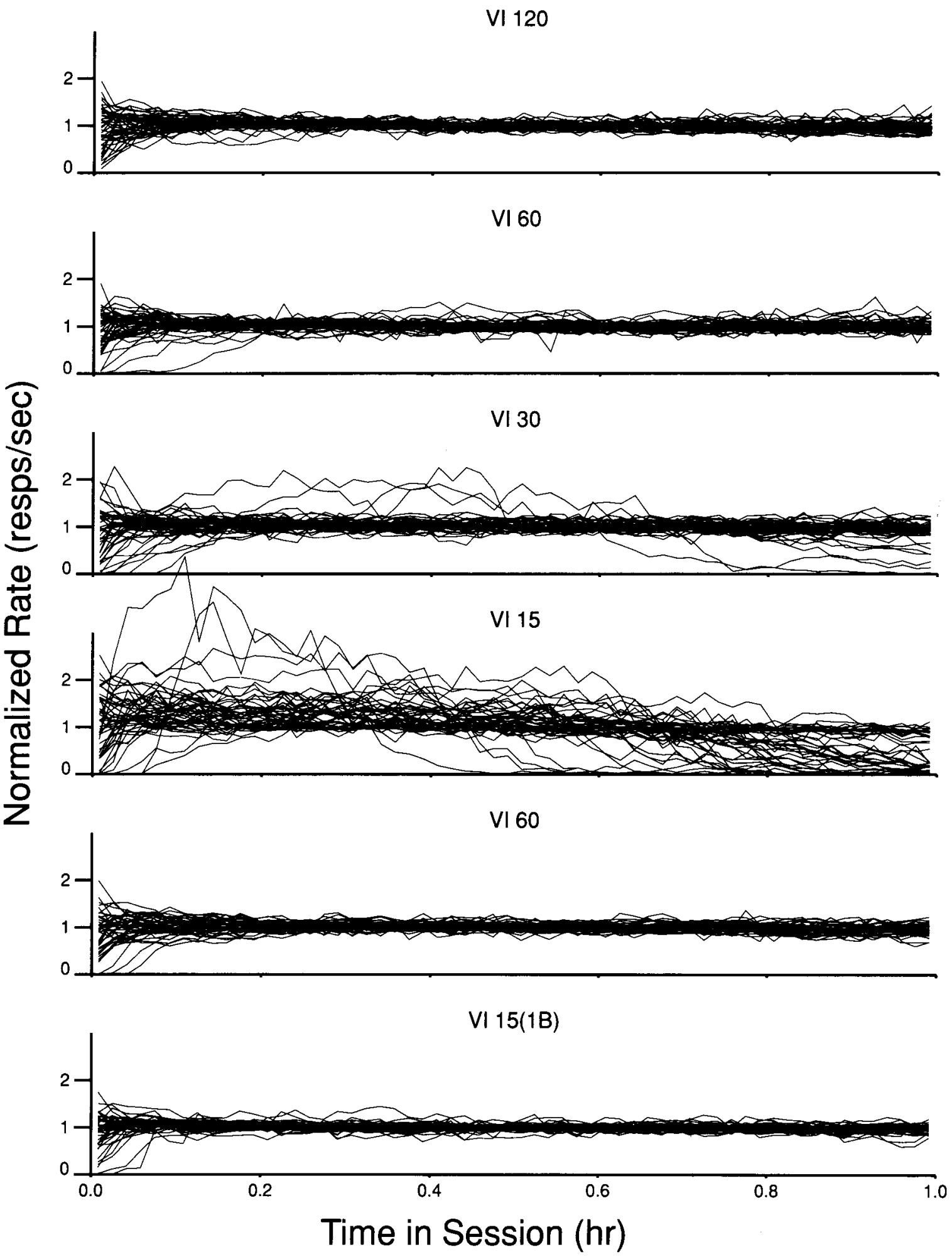

Figure 2. Each frame depicts the rate of the operant as a function of time in the session for each of the 45 birds. The consecutive procedures in the experiment are presented in consecutively lower frames. 
chamber. A white-noise generator provided ambient masking noise within the chamber. The houselights and keylights were off and the magazine light on during food presentation. Stimulus events were controlled and keypecks were recorded by a computer system (Walter \& Palya, 1984) as in Experiment 1.

Procedure. The birds were given their daily $60-\mathrm{min}$ exposure to the scheduled procedure whenever they were within $5 \%$ of their $80 \%$ free-feeding weights. Therefore, the birds were run between three and seven times per week. The reinforcer duration was $3 \mathrm{sec}$ throughout the experiment, except in Phase 6, noted below. The birds were exposed to their designated schedule for a minimum of 30 sessions ( 29 in one case). With a few exceptions, most birds received 30 sessions of exposure to each condition. The birds were continued under a procedure until there were no apparent trends in the last 5 days of their data as determined by a visual inspection of their performance, plotted as a function of sessions of exposure to the procedure.

The birds first received between 34 and 40 sessions of a simple VI 120-sec schedule based on a 20-element Fleshler-Hoffman series (Phase 1). The second phase consisted of 30-40 sessions of a VI 60 -sec schedule. The birds were then exposed to 29 to 38 sessions of a VI 30-sec schedule (Phase 3). In Phase 4, the birds were exposed to between 30 and 45 sessions of a VI 15 -see schedule. The birds were then returned to a VI 60-sec schedule for 30-37 sessions in Phase 5. The final procedure (Phase 6) implemented a VI I5-sec schedule with a reinforcement duration set to $1.5 \mathrm{sec}$ or $200 \mathrm{msec}$ after the eat beam was broken, whichever occurred first. This procedure limited the birds to typically one "bite" of food during each reinforcement cycle. Phase 6 was in effect for $30-40$ sessions.

\section{Results and Discussion}

Description of behavior. In general, the procedures of Experiment 2 indicated that when the number of food presentations in the fixed session length became large as the result of an increasing reinforcement rate, the distribution of responding across the session often showed a large bitonic rate change across the session. This was in contrast to the findings of the previous experiment, which had indicated that higher reinforcement rates did not result in more within-session curvature. In the previous experiment, the amount of food provided to each bird in a session had been restricted to no more than what was necessary to maintain that bird at its $80 \%$ weight by controlling the session length. In the present experiment, session length was fixed at $1 \mathrm{~h}$ regardless of the number of reinforcers available. For example, under the VI 15sec schedule, birds could receive approximately $2403-$ sec reinforcers within a $1-h$ period. Under those conditions, the within-session rate change was especially large in the smaller birds. Two-hundred and forty reinforcers is approximately five times the number typically used in this laboratory to maintain birds of that size at their $80 \%$ weight. Magazine activity logs indicated that many of the small birds ceased entering the magazine aperture before the end of the $1-h$ session.

Figure 2 provides a population perspective of the within-session rate change as a function of reinforcement rate (number of food presentations per session). Data from consecutive phases are presented in successively lower frames of the figure and are as labeled. Each of the consecutive frames presents the normalized rate of responding in each 60-sec bin as a function of time in the session for each of the 45 birds under the procedure specified. For example, the within-session rate change for the 45 birds under a VI 120 -sec schedule is given in the top frame.

The top frame shows that under a VI 120 -sec schedule, rate distributions across the session for most birds were relatively flat. The greatest bird-to-bird variability occurred in the first few minutes of the session. This can be seen by noting the divergence in the 45 functions in this frame at their leftmost extent (the beginning of the session). By scanning down the first four frames, one can see that the number of birds exhibiting a curvilinear rate change across the session increased with increases in reinforcement rate (number of food presentations per session). This can be seen by noting the progressive increase in the divergence of the 45 functions across the first four frames. The frame illustrating the within-session rate change under a VI 15-sec schedule clearly shows that the response rates for many birds initially rise and then subsequently drop to zero or near zero before the end of the 1 -h session. The fifth frame depicts the within-session distributions of responding obtained under the return to a VI 60-sec schedule. It shows that the performance of the birds basically returned to that obtained under the first implementation of this schedule (i.e., nearly all horizontal functions with the exception of the beginning of the session). This recovery of the population baseline indicated that the effect obtained under the VI 15-sec schedule was not attributable to the presentation order of the schedules.

The bottom frame of Figure 2 depicts the within-session rate change under the schedule which provided a high reinforcement rate (VI $15 \mathrm{sec}$ ), but only a short-duration access to the food ( 1 "bite"). This frame demonstrates that the reinforcement rate per se was not responsible for the fre-

Table 2

Median Within-Session Rate Change Indices and Variance Accounted for by Body Weight for the Procedures of Experiment 2

\begin{tabular}{|c|c|c|c|c|c|c|c|c|}
\hline \multirow[b]{2}{*}{ Schedule } & \multicolumn{2}{|c|}{ One Line } & \multicolumn{2}{|c|}{ First } & \multicolumn{2}{|c|}{ Second } & \multicolumn{2}{|c|}{ McSweeney } \\
\hline & Slope & $r^{2}$ & Slope & $r^{2}$ & Slope & $r^{2}$ & " $a$ " & $r^{2}$ \\
\hline VI 120 & -0.10 & -.02 & 0.59 & -.02 & -0.07 & -.01 & 0.31 & -.02 \\
\hline VI 60 & -0.09 & .08 & 0.35 & -.02 & -0.06 & .05 & 0.30 & .01 \\
\hline VI 30 & -0.11 & -.01 & 0.99 & -.02 & -0.10 & .06 & 0.39 & .14 \\
\hline VI 15 & -1.06 & .18 & -0.27 & -.01 & -1.26 & .11 & 0.98 & .15 \\
\hline V1 60 & -0.06 & -.01 & 0.99 & -.02 & -0.10 & -01 & 0.30 & -.01 \\
\hline VI $15(1 B)$ & -0.09 & .00 & 0.02 & -.02 & -0.04 & .07 & 0.30 & .04 \\
\hline
\end{tabular}


quency of curvilinear rate changes, in that a high reinforcement rate with limited access to food did not produce a high frequency of bitonic effects in the birds. Rather, it seems more appropriate to attribute the changes in the frequency of the bitonic within-session rate change to the increasing amount of food made available (and presumably eaten) during the session as the reinforcement rate increased.

Table 2 provides indices for the effects graphically illustrated in Figure 2. Each of the horizontal sections of the table provides the median index (as specified in its section label) for the within-session rate change under the schedule of reinforcement given in its row label (e.g., the median slope of a single line fit for the $\mathbf{4 5}$ birds under the VI 120-sec schedule). In addition, each section of the table also indicates the variance accounted for by the regression of the birds' body weights against their withinsession rate change index. The $r^{2}$ values were adjusted for the number of parameters; as a result, negative values were possible.

The first section of the table gives the median slopes for straight-line fits under each schedule, and the $r^{2}$ s for body weights against slopes of straight-line fits for each of those schedules. The slopes of the single line fits indicate a consistent shallow decline in response rate across the session with the exception of the slope under the VI 15 -sec schedule. The median VI 15-sec schedule slope showed a sharp decline over the session (i.e., -1.06 ). In contrast to this simple VI 15-sec schedule, the VI 15-sec one-bite procedure exhibited a shallow median slope which was comparable to the lower reinforcement rate schedules (i.e., -0.09 ). This quantifies the earlier visual indication given in Figure 2 that the cumulative access to food (and presumably the amount of food eaten) over the course of the session appears to be the more important determinant of the within-session rate change. This interpretation is further supported by the significant $r^{2}$ for the body weight by slope regression for the VI $15-\mathrm{sec}$ schedule (i.e., .18). Larger birds did not exhibit as much within-session rate change as did the smaller birds. The $r^{2}$ for the slope by weight for the initial implementation of the VI 60-sec schedule (but not the replication of the VI 60 -sec) was also significant. This indicated that body weight could be a relevant determinant of even modest slopes.

The second vertical section of the table illustrates the data based on the first segment of a two-line fit. The medians of the fits were positive with the exception of the VI 15-sec schedule which shows a negative slope. The birds' body weights were not correlated with the initial slope of the two-line fit. The last two portions of Table 2 illustrate the results obtained with the second segment of a two-line fit, and the rate loss parameter for McSweeney's model (i.e., "a"), respectively. These portions of the table demonstrate, with other indices, the same basic message as had been seen with the simple straight-line fit: (1) a VI 15-sec schedule produces substantial within-session rate changes, (2) the VI 15-sec one-bite schedule does not, and (3) the within-session rate change index under the VI 15-sec and VI 30-sec schedules was correlated with the weight of the bird.

\section{GENERAL DISCUSSION}

The experiments of the present study demonstrated that: (1) none of the 15 combinations of schedules and reinforcement rates produced a large within-session response rate change when the number of reinforcers in a session was restricted; (2) a high reinforcement rate with a long session length did result in a tendency toward a strongly bitonic rate change over a session, but that rate change was correlated with the bird's body weight; and finally (3) the same long exposures to a reinforcement rate which had produced strongly bitonic rate changes with normal reinforcement durations did not result in large withinsession rate changes if the bird's access to food was limited to one bite per reinforcer.

Taken together, these findings suggest that the degree of within-session rate change is a function of some factor correlated with the amount of food access in a session per unit of body weight. Such a process is consistent with what most researchers refer to when they use the term satiation. However, as McSweeney and her colleagues (McSweeney, Hinson, \& Cannon, 1996; Roll et al., 1995) have aptly pointed out, this is only a label for what is actually a poorly understood mechanism. For example, while the current usage of satiation comfortably fits the tendency for most birds to exhibit a rate loss across the session; the traditional meaning poorly fits the instances showing rate gains across the initial portion or even across the entire session.

McSweeney has argued that her theoretical approach is superior to the simple notion of satiation. Her position is that the initial rising portion of the within-session rate change is the result of sensitization and is best described by a positive hyperbola. The sustained rate loss across the major portion of a session is seen as habituation and best described by a negative exponential. Overall, the withinsession rate change is therefore described by the algebraic difference of those two processes. McSweeney has demonstrated the systematic character of her position by showing that the same model could describe both the change in a maintained operant across a session, as well as data from the sensitization and habituation literature (McSweeney, Hinson, \& Cannon, 1996).

On the basis of the assessment which could be made with the current data, McSweeney's quantitative model did not fare exceptionally well in fitting all of the withinsession rate changes likely to occur under normal running procedures. An adequate model must describe individual birds which may exhibit basically no rate change, an initial transient rate loss, a sustained rate gain throughout the entire session, or even a progressive change in the withinsession rate change with increasing exposure to the procedure. It should be noted, however, that the traditional alternative, satiation, fares worse. Not only does the sim- 
ple notion of satiation fail when there is a rate increase across the session, the notion of satiation fails to make any specific quantitative predictions at all.

There are three conceptual alternatives to the issue raised by McSweeney; they are as follows: (1) Retain the term satiation but clarify its specific definition and elaborate its specific functional properties. (2) Show that both satiation and a wide variety of other phenomena could be seen as instances of some more fundamental processes such as sensitization and habituation. Paradigmatic development within this second framework would entail adjusting definitions to fit the emerging empirical framework. And, finally (3) reify the traditional definition of satiation and therefore reject its appropriateness as an explanation for the within-session effect. Theoretical development within this third approach would be the elaboration of the referents for the terms sensitization and habituation and the systematization of their functional properties. McSweeney (McSweeney, Hinson, \& Cannon, 1996) has taken this third alternative. She has asserted that the within-session rate change is the result of sensitization and habituation rather than satiation and has rejected satiation as a useful term.

Unfortunately, the post hoc freedom of referent and absence of differential prediction when satiation and habituation are applied to the within-session effect negates the opportunity for an experimentum crucis intended to choose between those alternatives. For example, it could be argued that small amounts of food do not provide for as much habituation as do large amounts of food. Without principled, definitive specification of precisely what is and is not to be expected with the two terms or processes, any procedure which is thought to produce satiation could be said to actually be habituation rather than satiation.

In this light, the second conceptual approach to the issues pertaining to satiation and habituation appears to be the most productive. Satiation could be seen as a special case of habituation. Additionally, the terms satiation and habituation could be seen as empirically driven terms (i.e., their functional properties are still being accrued). From this perspective, the reification of the traditional definition of satiation seems unnecessarily narrow. An important implication of this conceptual approach is that neither term could be used as an explanation for the phenomena that are used to define its properties.

The importance of controlling, and ultimately understanding, motivational variables was clearly demonstrated by McSweeney when she showed that the function relating response rate to reinforcement rate may depend on temporal position in the session (McSweeney, 1992). In addition, McSweeney's reliable demonstration of the within-session rate change in maintained operants illustrates the ease of studying motivational variables by using common "off the shelf" operant methodology. Furthermore, there is a practical methodological implication of the start-up effect documented by McSweeney et al. (1990) and Palya (1992). Given the evidence, a researcher would be justified in routinely deleting the first portion of the data obtained in a session if estimates close to modal behavior were of interest.

The present study clarified the determinant of the within-session response rate change. That change is at least partly under the control of food access per unit of body weight during the session. This is what is typically implied by the term satiation. The issues pertaining to the effect which remain to be resolved are the development of a quantitative model for satiation or whatever label is given to the process, and the determination of a coherent way of dealing with the variability across individuals.

\section{REFERENCES}

Collier, G., Hirsch, E., \& Kanarek, R. (1977). The operant revisited. In W. K. Honig \& J. E. R. Staddon (Eds.), Handbook of operant behavior (pp. 28-52). Englewood Cliffs, NJ: Prentice-Hall.

FERSTER, C. B., \& SKINNER, B. F. (1957). Schedules of reinforcement. Englewood Cliffs, NJ: Prentice-Hall.

Fleshler, M., \& HofFMAN, H. S. (1962). A progression for generating variable-interval schedules. Journal of the Experimental Analysis of Behavior, 5, 529-530.

MCDOWELL, J. J., \& KESSEL, R. (1979). A multivariate rate equation for variable-interval performance. Journal of the Experimental Analysis of Behavior, 31, 267-284.

MCSWEENEY, F. K. (1992), Rate of reinforcement and session duration as determinants of within-session patterns of responding. Animal Learning \& Behavior, 20, 160-169.

MCSWeeney, F. K., HatField, J., \& Allen, T. M. (1990). Within-session responding as a function of post-session feedings. Behavioural Processes, 22, 177-186.

MCSWEeney, F. K., \& Hinson, J. M. (1992). Patterns of responding within sessions. Journal of the Experimental Analysis of Behavior, 58, 19-36.

McSweeney, F. K., Hinson, J. M., \& Cannon, C. B. (1996). Sensitizationhabituation may occur during operant conditioning. Psychological Bulletin, 120, 256-271.

MCSWEeney, F. K., \& Johnson, K. S. (1994). The effect of time between sessions on within-session patterns of responding. Behavioural Processes, 31, 207-218.

McSweeney, F. K., Roll, J. M., \& Cannon, C. B. (1994). The generality of within-session patterns of responding: Rate of reinforcement and session length. Animal Learning \& Behavior, 22, 252-266.

MCSWEENEY, F. K., Role, J. M., \& WeatherLy, J. N. (1994). Withinsession changes in responding during several simple schedules. Journal of the Experimental Analysis of Behavior, 62, 109-132.

McSweeney, F. K., Weatherly, J. N., \& Swindell, S. (1995). Prospective factors contribute little to within-session changes in responding. Psychonomic Bulletin \& Review, 2, 234-238.

MCSWEeney, F. K., Weatherly, J. N., \& SWindell, S. (1996). Withinsession changes in responding during delayed matching-to-sample and discrimination procedures. Animal Learning \& Behavior, 24, 290-299.

PALYA, W. L. (1992). Dynamics in the fine structure of schedule-controlled behavior. Journal of the Experimental Analysis of Behavior, 57, 267. 287.

Palya, W. L., \& Walter, D. E. (1993). A powerful, inexpensive experiment controller or IBM PC interface and experiment control language. Behavior Research Methods, Instruments, \& Computers, 25, $127-136$.

Press, W. H., Flannery, B. P., Teukolsky, S. A., \& VetTerling, W. T. (1989). Numerical recipes: The art of scientific computing (FORTRAN Version) (pp. 495-497). New York: Cambridge University Press.

RICHTER, C. P. (1927). Animal behavior and internal drives. Quarterly Review of Biology. 7, 91-96.

Roll, J. M., MCSWEeney, F. K., Johnson, K. S., \& Weatherly, I. N. (1995). Satiety contributes little to within-session decreases in responding. Learning \& Motivation, 26, 323-341. 
TRYon, W. W. (1982). A simplified time-series analysis for evaluating treatment interventions. Journal of Applied Behavior Analysis, 15, 423-429.

von Neumann, J., Kent, R. H., Bellinson, H. R., \& Hart, B. I (1941). The mean square successive difference. Annals of Mathematical Statistics, 12, 153-162.

Walter, D. E., \& Palya, W. L. (1984). An inexpensive experiment controller for stand-alone applications or distributed processing net- works. Behavior Research Methods, Instruments, \& Computers, 16, 125-134.

YounG, L. C. (1941). On randomness in ordered sequences. Annals of Mathematical Statistics, 12, 293-300.

(Manuscript received June 27, 1996;

revision accepted for publication December 16, 1996.) 